\title{
DARPP-32 Involvement in the Photic Pathway of the Circadian System
}

\author{
Lily Yan, ${ }^{1}$ Jessica M. Bobula, ${ }^{1}$ Per Svenningsson, ${ }^{2}$ Paul Greengard, ${ }^{2}$ and Rae Silver ${ }^{1,3,4}$ \\ ${ }^{1}$ Department of Psychology, Columbia University, New York, New York 10027, ${ }^{2}$ Laboratory of Molecular and Cellular Neuroscience, The Rockefeller

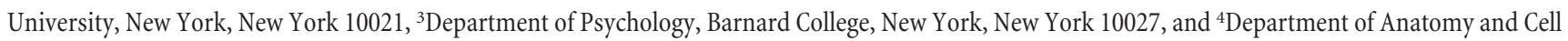 \\ Biology, College of Physicians and Surgeons, Columbia University, New York, New York 10032
}

The multifunctional regulator of protein kinases and phosphatases dopamine- and cAMP-regulated phosphoprotein of $32 \mathrm{kDa}$ (DARPP32 ) is an important molecular target of the dopamine signaling pathway. In the present study, we investigated the possible involvement of DARPP-32 regulation in the circadian system using DARPP-32 knock-out (KO) mice. These mice showed normal entrainment to a $12 \mathrm{~h}$ light/dark cycle and free run in constant darkness with a period similar to that of wild-type controls. After light exposure, however, the behavioral phase-delay response and the expression of light-induced clock gene mPer2 were attenuated in the DARPP-32 K0 mice. Attenuated phase delays were also seen in animals bearing a point mutation in DARPP-32 at the PKA (Thr34) but not at the casein kinase I (Ser130) phosphorylation site. We next examined DARPP-32 expression in the retina and intergeniculate leaflet (IGL), both of which convey light information to the suprachiasmatic nucleus (SCN), the locus of a master circadian clock, and in the SCN itself. DARPP-32 was expressed in the retina but not in the IGL or the SCN. The results indicate that DARPP-32 is involved in the retinal pathway transmitting photic information that resets the circadian clock.

Key words: DARPP-32; suprachiasmatic nucleus; phase shifts; circadian rhythm; photic transmission; retina

\section{Introduction}

The suprachiasmatic nucleus (SCN) is the locus of a master clock that organizes daily rhythms of physiology and behavior (Klein et al., 1991). The SCN is synchronized to the local environment by external cues, the most predictable of which is the daily light/dark (LD) cycle. Phase-setting photic input is conveyed from the eye to the SCN via a direct retinohypothalamic tract (RHT) and indirectly by the geniculohypothalamic tract (GHT) from the intergeniculate leaflet (IGL) (Moore and Lenn, 1972; Moore, 1982). The present objective was to explore the possible role of dopamine- and cAMP-regulated phosphoprotein of $32 \mathrm{kDa}$ (DARPP-32) in circadian rhythm generation and in providing phase-setting information to the circadian system.

DARPP-32, a multifunctional regulator of protein kinases and phosphatases, is an important molecular target of dopamine and is expressed in neurons receiving dopaminergic input (Walaas et al., 1983). DARPP-32 has, at least, four phosphorylation sites: Thr34, Thr75, Ser97, and Ser130. The multiple functions of DARPP-32 are achieved through phosphorylation at these sites. Phosphorylation by protein kinase A (PKA) at Thr34 converts DARPP-32 into a potent inhibitor of protein phosphatase-1 (PP-1) (Hemmings et al., 1984). The Ser97 and Ser130 sites can

Received June 16, 2006; revised Aug. 9, 2006; accepted Aug. 10, 2006.

This work was supported by National Institutes of Health Grants NS37919 (R.S.) and DA10044 (P.G.). We thank Drs. Paul Witkovsky, Joseph LeSauter, Michael Antle, Lino Saez, and Michael Young for their comments on the work and on a previous draft and Dr. Peter Ingrassia and Eun Young Choi for technical support.

Correspondence should be addressed to Dr. Rae Silver, Department of Psychology, Columbia University, 1190 Amsterdam Avenue, New York, NY 10027. E-mail: qr@columbia.edu.

DOI:10.1523/JNEUROSCI.2538-06.2006

Copyright $\odot 2006$ Society for Neuroscience $\quad$ 0270-6474/06/269434-05\$15.00/0 be phosphorylated by casein kinases I and II, respectively, leading to increased Thr34 phosphorylation (Girault et al., 1989; Desdouits et al., 1995). Phosphorylation at the Thr75 site inhibits PKA-induced phosphorylation at Thr34 (Bibb et al., 1999). The activated or inhibited DARPP-32/PP-1 pathway regulates the activity of a large array of downstream physiological effectors, including neurotransmitter receptors, voltage-gated ion channels, ion pumps, and transcriptional factors (Greengard, 2001; Svenningsson et al., 2004).

Dopamine signaling has been implicated in circadian rhythm regulation. Deficient light-masking response of dopamine $\mathrm{D}_{2}$ receptor knock-out $(\mathrm{KO})$ mice suggests that the dopamine pathway is essential for light masking of circadian rhythms (Doi et al., 2006). Dopaminergic signals may reach the circadian system through a retinal or an SCN site of action. In the retina, dopamine plays an important role in light adaptation (Witkovsky, 2004), and dopamine regulates the rhythmic expression of melanopsin, a photopigment of intrinsically photosensitive retinal ganglion cells (Sakamoto et al., 2005). In the SCN, dopaminergic $\mathrm{D}_{1}$ receptors are present in both fetuses and adults (Weaver et al., 1992; Ishida et al., 2002), but the phase-resetting effect of dopamine is seen only prenatally (Viswanathan et al., 1994). Finally, in cultured cell lines, dopamine signals enhance the transactivation potentials of CLOCK:BMAL1, the primary positive regulator of the molecular clock (Yujnovsky et al., 2006).

To examine the possible functional significance of DARPP-32 in circadian rhythmicity and photic entrainment, we compared the responses of wild-type (WT), DARPP-32 KO (Fienberg and Greengard, 2000), and phosphomutant DARPP-32 mice (Svenningsson et al., 2003). The results indicate that DARPP-32 KO 
A

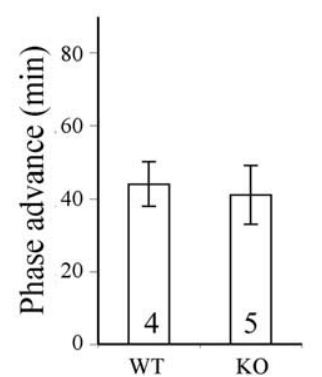

B

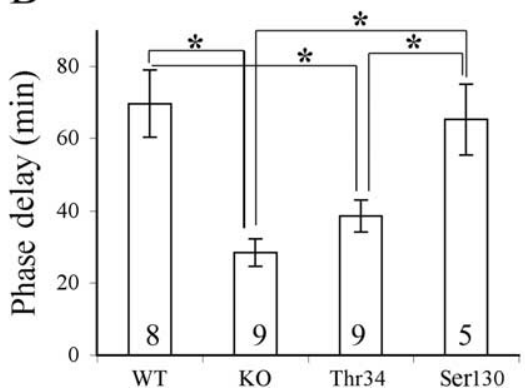

Figure 1. Phase shifting of wheel-running activity after an advancing (CT 22) or delaying (CT 16) light pulse (300 lux for 30 min) during subjective night. $\boldsymbol{A}$, Phase-advance response. $\boldsymbol{B}$, Phase-delay response after $3 \mathrm{~d}$ in DD by WT, DARPP-32 K0, and mice bearing a point mutation in Thr34 or Ser130. C, Actograms show phase-delay response of representative WT (top) or DARPP-32 KO (bottom) mice after a light pulse (LP) on the third day of DD. Data are presented as mean \pm SEM. Numbers on the histogram indicate the sample size. ${ }^{*} p<0.0125$ (Bonferroni-corrected for multiple comparisons). The gray area in $\boldsymbol{C}$ indicates the dark phase.

mice have attenuated behavioral phase delays and light-induced expression of mPer 2 mRNA in the SCN. Importantly, the results show that DARPP-32 mRNA was expressed in the retina, but not in the SCN or IGL. Our results provide the first evidence that DARPP-32 is involved in the retinal pathway transmitting photic signals to SCN.

\section{Materials and Methods}

Animals and housing. Male DARPP-32 KO mice, the Ser130 and Thr34 point mutants, and their WT littermate controls (C57BL/6 background) were studied at $\sim 5$ weeks of age. All mice have been described previously (Fienberg and Greengard, 2000; Svenningsson et al., 2003). Mice were housed in a $12 \mathrm{~h} \mathrm{LD} \mathrm{(300} \mathrm{lux)} \mathrm{cycle} \mathrm{for} \mathrm{2-4} \mathrm{weeks} \mathrm{before} \mathrm{being} \mathrm{used} \mathrm{in} \mathrm{the}$ experiments. Food and water were available ad libitum. All experimental procedures were approved by the Institutional Animal Care and Use Committee of Columbia University.

For behavioral studies, mice were housed individually, and their wheel-running behavior was monitored using DataQuest (Data Services, St. Paul, MN); the data were analyzed using Clocklab (Actimetrics, Evanston, IL). First, we entrained the WT and KO mice ( $n=10$ per group) in LD for 2 weeks and then transferred them to constant dark (DD) for another 2 weeks to determine their free-running period. Next, we assigned each genotype to two groups that were exposed to a light pulse (300 lux for $30 \mathrm{~min}$ ) at either circadian time 16 (CT 16) or CT 22. In the next study, animals of four different genotypes (WT and KO, Ser130, and Thr34 mutants; $n=10$ per group) were entrained to the LD cycle, transferred to DD, and exposed to a light pulse at CT 16 on the third day in $\mathrm{DD}$, to assess their phase-delay response.

For mRNA analysis, DARPP-32 KO and WT animals $(n=4$ per group) were exposed to a light pulse at CT 16 on the third day in DD and killed 90 min later (CT 17.5). Control animals were killed at the same time but did not receive light exposure.

In situ hybridization using digoxigenin-labeled $c R N A$ probes. Mice were deeply anesthetized (pentobarbital; $200 \mathrm{mg} / \mathrm{kg}$ ) under a red safe light $(<1$ lux $)$ and perfused intracardially with $10 \mathrm{ml}$ of saline and $20 \mathrm{ml}$ of a fixative ( $4 \%$ paraformaldehyde in $0.1 \mathrm{~m}$ phosphate buffer, $\mathrm{pH} 7.4$ ). The brains were removed, postfixed, and cryoprotected for $48 \mathrm{~h}$. To assess light-induced mPer 1 and mPer 2 expression, serial coronal sections (40 $\mu \mathrm{m}$ ) were made from the rostral to the caudal end of the SCN using a cryostat (Reichert-Jung, Heidelberg, Germany), and alternate sections were collected for each probe. To investigate DARPP-32 expression in the brain, $40 \mu \mathrm{m}$ sections at the level of SCN and IGL were collected. The IGL was defined precisely by processing alternate sections for NPY immunostaining (Takatsuji and Tohyama, 1989). To examine the retina, the cornea and lens were removed from the eye, and the eyecups were postfixed, cryoprotected, and sectioned at $40 \mu \mathrm{m}$.

The cRNA probes for mPer1 (nucleotide position 538-1752), mPer2 (1-638), and DARPP-32 (424-910) were synthesized with a standard

C

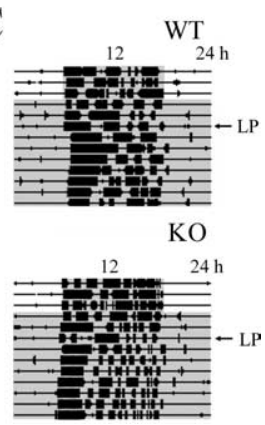

protocol (Yan et al., 1999). In situ hybridization was performed as described previously (Yan et al., 1999; Yan and Silver, 2002). For each of these transcripts, sense probes revealed no staining.

Immunocytochemistry of NPY. For NPY immunocytochemistry (ICC), sections were incubated in the NPY antibody (1:10,000; generated in rabbit; INCSTAR, Stillwater, MN) for $48 \mathrm{~h}$ at $4^{\circ} \mathrm{C}$ and then in Cy3 (cyanine 3)-donkey antirabbit antibody (1:200; Jackson ImmunoResearch, West Grove, PA) for $2 \mathrm{~h}$ at room temperature. After the ICC reaction, sections were coverslipped with Krystalon (EM Diagnostic Systems, Gibbstown, NH).

Laser-capture microdissection of SCN tissue, $R N A$ extraction, and reverse transcription-PCR. Fresh frozen forebrains were cut at $8 \mu \mathrm{m}$, and the sections containing SCN were mounted on uncharged glass slides (VWR Scientific, West Chester, PA). The sections were thawed at room temperature and fixed in 75\% ethanol. The sections were then stained and dehydrated with HistoGene laser-capture microdissection (LCM) frozen section staining kit (Arcturus Bioscience, Mountain View, CA). LCM of SCN tissue was performed using a Pixcell II laser-capture microscope (Arcturus Bioscience) with standard procedure (Emmert-Buck et al., 1996). After visually identifying the SCN region, the SCN tissue was lifted by a brief laser pulse and captured into a CapSure LCM cap (Arcturus Bioscience). Approximately forty SCN sections from five animals were pooled, and the total RNA was isolated using a PicoPure RNA isolation kit (Arcturus Bioscience). cDNA was synthesized using a RETROscript kit (Ambion, Austin, TX), and the quality of the cDNA was evaluated by a cDNA integrity kit (Kirkegaard \& Perry Laboratories, Gaithersburg, MD). PCR was performed using a GeneAmp 2400 system (PerkinElmer, Wellesley, MA).

Quantitative analysis. To assess mPer1 and mPer2 levels, images of SCN were captured using a CCD video camera [Sony (Tokyo, Japan) XC77] attached to a light microscope (BH-2; Olympus Optical, Tokyo, Japan). Optical density (OD) was quantified using the NIH Image program (version 1.61). The difference between SCN density and background was used as the OD value for each section. The averaged OD value of the sections from each brain was used as the OD value for one animal.

\section{Results}

\section{DARPP-32 KO mice show attenuated phase delays}

There were no significant differences in entrainment or freerunning behavior between DARPP-32 KO mice and their WT littermates, although they did differ in their phase-shifting behavior. Under LD, the total running activity of the WT mice was higher than that of the $\mathrm{KO}$; however, the difference was not statistically significant $\left(32 \pm 6 \times 10^{3}\right.$ vs $24 \pm 2 \times 10^{3}$ wheel rotations/d; $p>0.05$ ). Both WT and KO mice run predominantly during the dark phase $(95.9 \pm 1.3$ vs $93.6 \pm 1.6 \% ; p>0.05)$. Under DD, the free-running period of the KO mice was about the same as that of their WT littermates $(23.84 \pm 0.14$ vs $23.9 \pm$ $0.16 \mathrm{~h} ; p>0.05)$. We further examined the photic response of these animals using a brief light exposure. After light exposure at CT 22, there was no significant difference in the phase advances between the DARPP-32 KO and WT mice (Fig. $1 A$ ). In contrast, a light pulse at CT 16 revealed significant differences in the phasedelay response between WT and DARPP-32 KO mice (Fig. $1 B$ ).

Comparison of $\mathrm{WT}, \mathrm{KO}$, and mutant animals with a point mutation at either the Ser 130 or the Thr34 phosphorylation site of DARPP-32 indicated a similar phase-delay response in the Ser130 mutant and WT mice, whereas the phase delay of the Thr34 mutant was significantly less than WT but about the same as that of the DARPP-32 KO mice (Fig. $1 B$ ). 
A
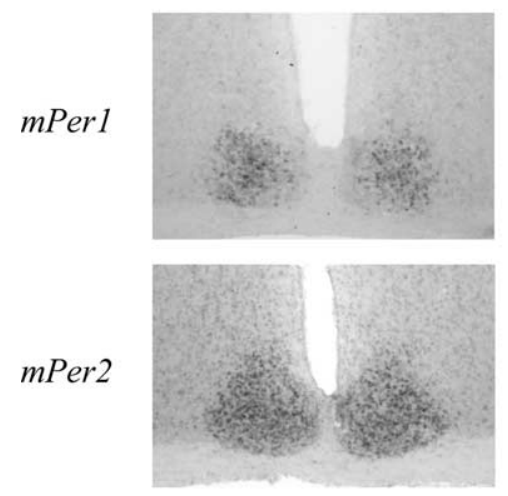

B

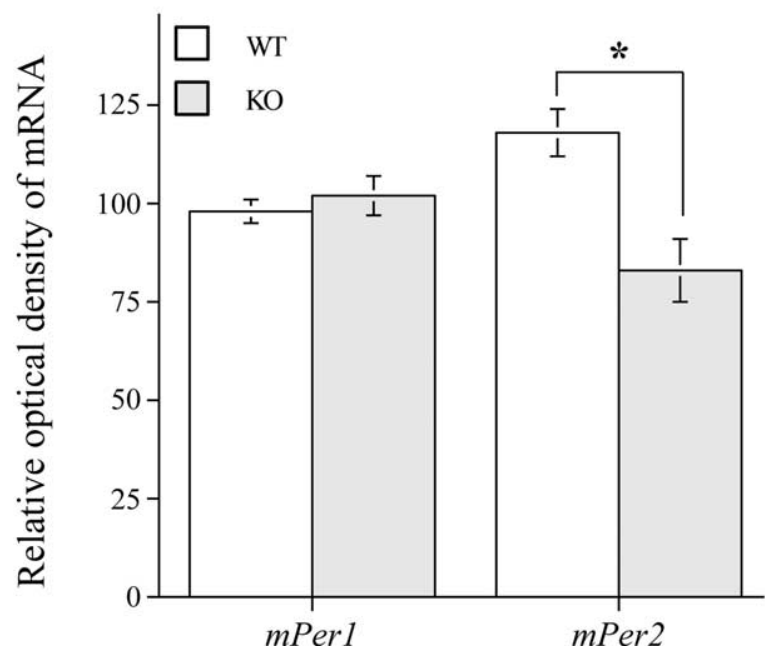

Figure 2. Representative photomicrographs $(\boldsymbol{A})$ and quantification $(\boldsymbol{B})$ of $m$ Per1 and $m$ Per2 mRNA in the SCN using in situ hybridization. Animals ( $n=4$ per group) were given a light pulse (300 lux for $30 \mathrm{~min}$ ) at (T 16 and killed $90 \mathrm{~min}$ after the beginning of the light pulse. Alternate SCN sections from each animal were processed with mPer 1 and $m P e r 2$ in situ probes, respectively. Scale bar, $300 \mu \mathrm{m}$. Data are presented as mean \pm SEM. ${ }^{*} p<0.05$, two-sample $t$ test.

\section{mPer 1 and mPer 2 mRNA expression after phase-delaying light pulses}

There was no significant difference in induction of mPerl in the SCN of DARPP-32 KO and WT mice (Fig. 2). In contrast, mPer2 staining in the SCN was reduced in the DARPP-32 KO mice (Fig. 2). In both WT and KO strains, there were only a few cells labeled with mPer 1 or $m$ Per 2 in the SCN of control animals that were not exposed to a light pulse, as reported previously (Yan and Silver, 2002).

\section{DARPP-32 mRNA expression in the SCN, IGL, and retina}

$D A R P P-32$ mRNA expression was examined by in situ hybridization in the SCN and in the retina and IGL, regions related to photic transduction in the circadian system. In contrast to the strong in situ signal in the striatum (Fig. 3A,B), DARPP-32 expression was not detected in the SCN (Fig. $3 A, C$ ) or IGL (Fig. $3 D$ ) during subjective day (CT 4 ). We also examined animals during nighttime and after light exposure at CT 16 but did not detect any DARPP-32 mRNA expression in SCN or IGL (data not shown). In contrast to the findings for the SCN, cells of the proximal portion of the inner nuclear layer (INL) of the retina, at the border with the inner plexiform layer, were $D A R P P-32$ positive (Fig. $3 F$ ).

To confirm the in situ results, we further examined DARPP-32 expression in the SCN by reverse transcription-PCR using lasercaptured SCN tissue. The results indicate that DARPP-32 was expressed in forebrain used as control tissue but not in the SCN from the same PCR run (data not shown).

\section{Discussion}

The present results demonstrate that DARPP-32 KO mice displayed attenuated phase delays to light exposure, suggesting that their photic response is impaired. Furthermore, mice bearing a point mutation at Thr34 (but not Ser130 mutants) have the same deficit as do the DARPP-32 KO mice. These results suggest that DARPP-32 is a component of the pathway mediating the photic response and also suggest that phosphorylation of Thr34 and activation of the downstream pathway is the responsible site of action. In the SCN, light-induced mPer 2 expression was also attenuated in the DARPP-32 KO mice compared with that observed in WT controls. DARPP-32 mRNA was observed in the retina but was not detectable in the SCN or IGL. Together, our results suggest that DARPP-32 signaling is important within the retina, in relation to the photic input pathway to the SCN, but does not act directly on the SCN.

The phase-advance component of the response to light was not affected in the DARPP-32 KO mice. The phase-response curve of C57 mice has a high amplitude of phase delay of $\sim 1.1 \mathrm{~h}$ and a low amplitude of phase advance of $0.5 \mathrm{~h}$ (Schwartz and Zimmerman, 1990). The lack of difference between the WT and DARPP-32 KO animals may be attributable to the low amplitude of the response. Alternatively, it may be that phase delays and advances involve different signaling pathways and clock genes (Prosser et al., 1989; Ding et al., 1998; Albrecht et al., 2001). Our results are consistent with the latter conclusion and suggest that DARPP-32 participates in the pathways mediating phase delays but not those underlying phase advances.

In DARPP-32 KO mice, we found decreased mPer 2 induction by light. This is in agreement with previous studies suggesting a relationship between the light-induced mPer2 gene and the phase-delay response (Albrecht et al., 2001; Yan and Silver, 2002; Yan et al., 2003). It is unlikely that there are differences in mPer1 induction between the DARPP-32 KO and WT mice at time points not examined here, because the peak response occurs after 90 min of light exposure for both mPer 1 and mPer2 (Takumi et al., 1998; Yan and Silver, 2002).

\section{DARPP-32 is not directly involved in SCN clock function}

It is well documented that DARPP-32 is localized in neurons receiving dopaminergic input, with few exceptions (Ouimet et al., 1984). Dopaminergic input is absent in the adult SCN (Ishida et al., 2002), although dopamine $D_{1}$ receptors are present in both the fetal and adult SCN (Weaver et al., 1992; Ishida et al., 2002). Dopaminergic regulation participates in the entrainment of the fetal circadian clock. Periodic treatment with a dopamine $D_{1}$ receptor agonist can entrain the fetuses of SCN-lesioned dams (Viswanathan et al., 1994). Activation of $\mathrm{D}_{1}$ receptors activates c-Fos expression in the fetal SCN but not after postnatal day 2, the time at which RHT innervation to the SCN occurs and photic entrainment begins (Weaver et al., 1992, 1995). These results indicate a transition from dopaminergic to photic regulation during development. Together, these results suggest that dopamine and DARPP-32 signaling do not directly regulate the clock function within the adult SCN. 

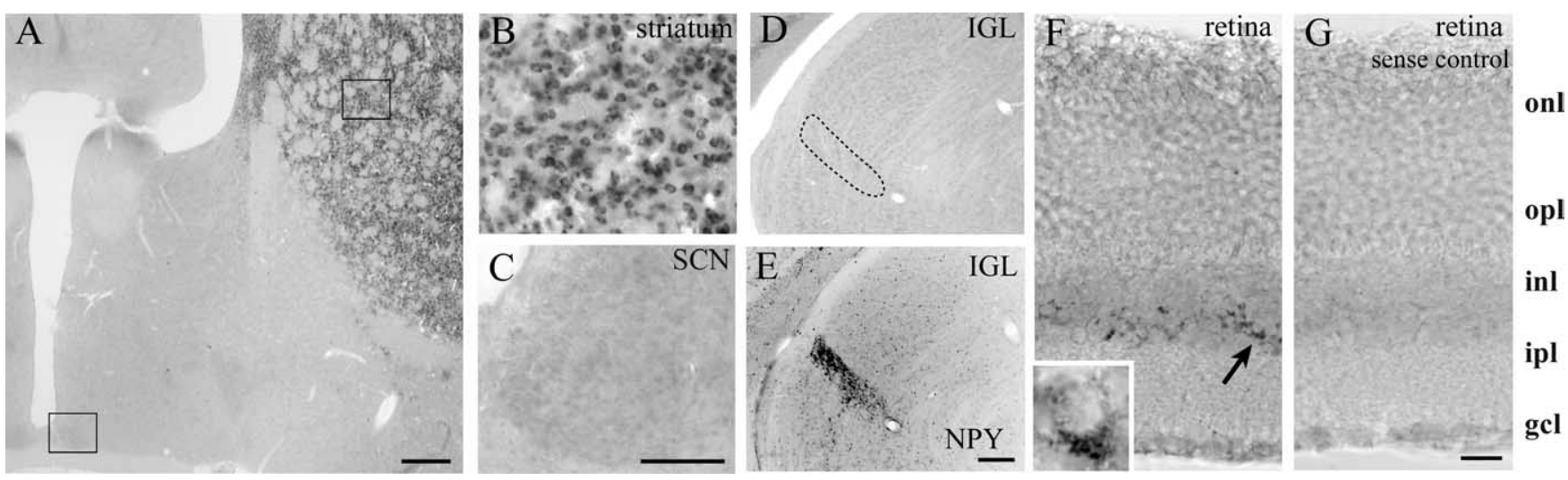

Figure 3. Expression of DARPP-32 mRNA in SCN, striatum, IGL, and retina. $A$, Coronal section showing robust DARPP- 32 staining in the striatum and its absence in the SCN. The box in $\boldsymbol{A}$ delineates the area shown in higher-power images of striatum and $S C N$ in $\boldsymbol{B}$ and $\boldsymbol{C}$, respectively. D, DARPP-32 is not expressed in the IGL (delineated by a dashed line). $\boldsymbol{E}$, NPY staining in the section adjacent to that shown in $\boldsymbol{D}$ was used to delineate the IGL. $\boldsymbol{F}$, DARPP-32 is expressed in the proximal portion of the inner nuclear layer. $\boldsymbol{F}$, Inset, High-power image of a DARPP-32-stained cell. $\boldsymbol{G}$, When using a sense probe, no DARPP-32 staining was seen in the retina. onl, Outer nuclear layer; opl, outer plexiform layer; inl, inner nuclear layer; ipl, inner plexiform layer; $g c l$, ganglion cell layer. Scale bars, $\boldsymbol{A}, \boldsymbol{E}$ (for $\boldsymbol{D}, \boldsymbol{E}), 300 \mu \mathrm{m} ; \boldsymbol{C}($ for $\boldsymbol{B}, \boldsymbol{C}), 100 \mu \mathrm{m} ; \boldsymbol{G}$ (for $\boldsymbol{F}, \boldsymbol{G}), 20 \mu \mathrm{m}$.

\section{DARPP-32 mediates photic information in the retina}

The retina sends photic information to the SCN directly through the RHT (Moore and Lenn, 1972), which originates from a subset of retinal ganglion cells (Gooley et al., 2001). We did not observe DARPP-32 in these intrinsically photosensitive ganglion cells but did find DARPP-32 mRNA expression in the proximal portion of the INL, in which the amacrine cells are located. This is in agreement with the finding of DARPP-32-like immunoreactivity in the AII amacrine cells of INL in rat retina (Partida et al., 2004) and mouse retina (P. Witkovsky and R. Silver, unpublished data). AII amacrine cells are a component of the pathway transmitting information from rod photoreceptors. Rod photoreceptor signals are conveyed through rod bipolar cells to AII amacrine cells. The output of the AII amacrine cells differentially affect $\mathrm{ON}$ and OFF of cone bipolar cells, thereby altering the responses of ON and OFF of ganglion cells (Bloomfield and Dacheux, 2001). Melanopsin-containing photoreceptor cells in the ganglion layer and the traditional rod and cone photoreceptor cells both contribute to photic transduction of the circadian system (Hattar et al., 2003; Panda et al., 2003). It has been suggested in a study using the pseudorabies virus tract tracing method that amacrine cells in the retina also contribute to circadian response to light (Provencio et al., 1998).

Our results suggest a retinal site of DARPP-32 action involved in the attenuation of phase delays seen in the $\mathrm{KO}$ and Thr34 mutants. However, it should be noted that DARPP-32 is widely distributed in the brain, including cortex, thalamus, and hypothalamus subregions, and these brain regions send projections to various target areas (Svenningsson et al., 2004). The DARPP-32 containing cells and their targets in the brain may influence the $\mathrm{SCN}$ function indirectly through either neuronal or humoral pathways.

\section{Significance of Thr34 phosphorylation of DARPP-32}

DARPP-32 can be regulated by various neurotransmitters, neuromodulators, and neuropeptides. Dopamine, serotonin, GABA, adenosine, nitric oxide, and neurotensin can increase the phosphorylation of the Thr34 site (Svenningsson et al., 2004). When phosphorylated at Thr34, DARPP-32 is converted into an inhibitor of PP-1 (Hemmings et al., 1984). PP-1 controls the phosphorylation state and physiological activities of many substrates. Thus, the neurotransmitters that increase DARPP-32 phosphor- ylation at Thr34 inhibit PP-1 activity and regulate a downstream cascade that involves receptors, ion channels, and transcription factors (Greengard, 2001).

\section{Dopamine signaling in retinal function}

Dopamine is a chemical messenger for adaptation to light (Witkovsky, 2004). Dopaminergic interneurons are found in the retinas of all vertebrate classes (Ehinger, 1983; Brecha et al., 1984; Marc, 1986) and affect retinal synaptic pathways and signal processing through dopamine receptors (Witkovsky and Schèutte, 1991). Dopamine $D_{1}$ and $D_{2}$ receptors are distributed throughout the retina (Witkovsky, 2004). Dopamine $\mathrm{D}_{2}$ receptor KO mice display impaired light masking but intact phase delays, supporting a role for the $\mathrm{D}_{2}$ receptor in masking of circadian rhythms (Doi et al., 2006). The effect of dopamine on phosphorylation of DARPP-32 at Thr34 site is bidirectional, with dopamine $\mathrm{D}_{1}$ receptors being stimulatory and $\mathrm{D}_{2}$ receptors inhibitory (Svenningsson et al., 2004). Given this inhibitory action of $\mathrm{D}_{2}$ receptors on Thr34-DARPP-32, it is not surprising that the behavioral responses of DARPP-32 KO and Thr34 mutants are different from those of $\mathrm{D}_{2}$-receptor $\mathrm{KO}$ mice. The present study indicates an attenuated behavioral phase-delay response in the DARPP-32 KO mice after nighttime light exposure and the expression of DARPP-32 in the retina but not in the SCN or IGL. DARPP-32 is found in amacrine cells (Partida et al., 2004), and AII amacrine cells are dopamine sensitive (Witkovsky, 2004). Although dopamine signaling has been well studied in the retina, the present results provide the first functional evidence of a role for DARPP-32 in the circadian response to light.

\section{References}

Albrecht U, Zheng B, Larkin D, Sun ZS, Lee CC (2001) MPer1 and mper2 are essential for normal resetting of the circadian clock. J Biol Rhythms 16:100-104.

Bibb JA, Snyder GL, Nishi A, Yan Z, Meijer L, Fienberg AA, Tsai LH, Kwon YT, Girault JA, Czernik AJ, Huganir RL, Hemmings Jr HC, Nairn AC, Greengard P (1999) Phosphorylation of DARPP-32 by Cdk5 modulates dopamine signalling in neurons. Nature 402:669-671.

Bloomfield SA, Dacheux RF (2001) Rod vision: pathways and processing in the mammalian retina. Prog Retin Eye Res 20:351-384.

Brecha NC, Oyster CW, Takahashi ES (1984) Identification and characterization of tyrosine hydroxylase immunoreactive amacrine cells. Invest Ophthalmol Vis Sci 25:66-70.

Desdouits F, Siciliano JC, Greengard P, Girault JA (1995) Dopamine- and 
cAMP-regulated phosphoprotein DARPP-32: phosphorylation of Ser137 by casein kinase I inhibits dephosphorylation of Thr-34 by calcineurin. Proc Natl Acad Sci USA 92:2682-2685.

Ding JM, Buchanan GF, Tischkau SA, Chen D, Kuriashkina L, Faiman LE, Alster JM, McPherson PS, Campbell KP, Gillette MU (1998) A neuronal ryanodine receptor mediates light-induced phase delays of the circadian clock. Nature 394:381-384.

Doi M, Yujnovsky I, Hirayama J, Malerba M, Tirotta E, Sassone-Corsi P, Borrelli E (2006) Impaired light masking in dopamine D2 receptor-null mice. Nat Neurosci 9:732-734.

Ehinger B (1983) Connexions between retinal neurons with identified neurotransmitters. Vision Res 23:1281-1291.

Emmert-Buck MR, Bonner RF, Smith PD, Chuaqui RF, Zhuang Z, Goldstein SR, Weiss RA, Liotta LA (1996) Laser capture microdissection. Science 274:998-1001.

Fienberg AA, Greengard P (2000) The DARPP-32 knockout mouse. Brain Res Brain Res Rev 31:313-319.

Girault JA, Hemmings Jr HC, Williams KR, Nairn AC, Greengard P (1989) Phosphorylation of DARPP-32, a dopamine- and cAMP-regulated phosphoprotein, by casein kinase II. J Biol Chem 264:21748-21759.

Gooley JJ, Lu J, Chou TC, Scammell TE, Saper CB (2001) Melanopsin in cells of origin of the retinohypothalamic tract. Nat Neurosci 4:1165.

Greengard P (2001) The neurobiology of slow synaptic transmission. Science 294:1024-1030.

Hattar S, Lucas RJ, Mrosovsky N, Thompson S, Douglas RH, Hankins MW, Lem J, Biel M, Hofmann F, Foster RG, Yau KW (2003) Melanopsin and rod-cone photoreceptive systems account for all major accessory visual functions in mice. Nature 424:76-81.

Hemmings Jr HC, Greengard P, Tung HY, Cohen P (1984) DARPP-32, a dopamine-regulated neuronal phosphoprotein, is a potent inhibitor of protein phosphatase-1. Nature 310:503-505.

Ishida Y, Yokoyama C, Inatomi T, Yagita K, Dong X, Yan L, Yamaguchi S, Nagatsu I, Komori T, Kitahama K, Okamura H (2002) Circadian rhythm of aromatic L-amino acid decarboxylase in the rat suprachiasmatic nucleus: gene expression and decarboxylating activity in clock oscillating cells. Genes Cells 7:447-459.

Klein DC, Moore RY, Reppert SM, eds (1991) Suprachiasmatic nucleus: the mind's clock. New York: Oxford UP.

Marc RE (1986) Neurochemical stratification in the inner plexiform layer of the vertebrate retina. Vision Res 26:223-238.

Moore RY (1982) The suprachiasmatic nucleus and the organization of a circadian system. Trends Neurosci 5:404-407.

Moore RY, Lenn NJ (1972) A retinohypothalamic projection in the rat. J Comp Neurol 146:1-14.

Ouimet CC, Miller PE, Hemmings Jr HC, Walaas SI, Greengard P (1984) DARPP-32, a dopamine- and adenosine $3^{\prime}: 5^{\prime}$-monophosphate-regulated phosphoprotein enriched in dopamine-innervated brain regions. III. Immunocytochemical localization. J Neurosci 4:111-124.

Panda S, Provencio I, Tu DC, Pires SS, Rollag MD, Castrucci AM, Pletcher MT, Sato TK, Wiltshire T, Andahazy M, Kay SA, Van Gelder RN, Hogenesch JB (2003) Melanopsin is required for non-image-forming photic responses in blind mice. Science 301:525-527.

Partida GJ, Lee SC, Haft-Candell L, Nichols GS, Ishida AT (2004) DARPP32-like immunoreactivity in AII amacrine cells of rat retina. J Comp Neurol 480:251-263.
Prosser RA, McArthur AJ, Gillette MU (1989) cGMP induces phase shifts of a mammalian circadian pacemaker at night, in antiphase to cAMP effects. Proc Natl Acad Sci USA 86:6812-6815.

Provencio I, Cooper HM, Foster RG (1998) Retinal projections in mice with inherited retinal degeneration: implications for circadian photoentrainment. J Comp Neurol 395:417-439.

Sakamoto K, Liu C, Kasamatsu M, Pozdeyev NV, Iuvone PM, Tosini G (2005) Dopamine regulates melanopsin mRNA expression in intrinsically photosensitive retinal ganglion cells. Eur J Neurosci 22:3129-3136.

Schwartz WJ, Zimmerman P (1990) Circadian timekeeping in BALB/c and C57BL/6 inbred mouse strains. J Neurosci 10:3685-3694.

Svenningsson P, Tzavara ET, Carruthers R, Rachleff I, Wattler S, Nehls M, McKinzie DL, Fienberg AA, Nomikos GG, Greengard P (2003) Diverse psychotomimetics act through a common signaling pathway. Science 302:1412-1415.

Svenningsson P, Nishi A, Fisone G, Girault JA, Nairn AC, Greengard P (2004) DARPP-32: an integrator of neurotransmission. Annu Rev Pharmacol Toxicol 44:269-296.

Takatsuji K, Tohyama M (1989) The organization of the rat lateral geniculate body by immunohistochemical analysis of neuroactive substances. Brain Res 480:198-209.

Takumi T, Taguchi K, Miyake S, Sakakida Y, Takashima N, Matsubara C, Maebayashi Y, Okumura K, Takekida S, Yamamoto S, Yagita K, Yan L, Young MW, Okamura H (1998) A light-independent oscillatory gene mPer3 in mouse SCN and OVLT. EMBO J 17:4753-4759.

Viswanathan N, Weaver DR, Reppert SM, Davis FC (1994) Entrainment of the fetal hamster circadian pacemaker by prenatal injections of the dopamine agonist SKF 38393. J Neurosci 14:5393-5398.

Walaas SI, Aswad DW, Greengard P (1983) A dopamine- and cyclic AMPregulated phosphoprotein enriched in dopamine-innervated brain regions. Nature 301:69-71.

Weaver DR, Rivkees SA, Reppert SM (1992) $D_{1}$-dopamine receptors activate c-fos expression in the fetal suprachiasmatic nuclei. Proc Natl Acad Sci USA 89:9201-9204.

Weaver DR, Roca A, Reppert SM (1995) C-fos and jun-B mRNAs are transiently expressed in fetal rodent suprachiasmatic nucleus following dopaminergic stimulation. Brain Res Dev Brain Res 85:293-297.

Witkovsky P (2004) Dopamine and retinal function. Doc Ophthalmol 108:17-40.

Witkovsky P, Schèutte M (1991) The organization of dopaminergic neurons in vertebrate retinas. Vis Neurosci 7:113-124.

Yan L, Silver R (2002) Differential induction and localization of mPerl and mPer2 during advancing and delaying phase shifts. Eur J Neurosci 16:1531-1540.

Yan L, Takekida S, Shigeyoshi Y, Okamura H (1999) Per1 and Per2 gene expression in the rat suprachiasmatic nucleus: circadian profile and the compartment-specific response to light. Neuroscience 94:141-150.

Yan L, Hochstetler KJ, Silver R, Bult-Ito A (2003) Phase shifts and Per gene expression in mouse suprachiasmatic nucleus. Neuroreport 14:1247-1251.

Yujnovsky I, Hirayama J, Doi M, Borrelli E, Sassone-Corsi P (2006) Signaling mediated by the dopamine D2 receptor potentiates circadian regulation by CLOCK:BMAL1. Proc Natl Acad Sci USA 103:6386-6391. 